\title{
The "ELBA" project - eco-friendly mobility services for people and goods in small islands
}

\author{
P. Mancuso, G. Costagli \& C. Casella \\ Piombino - Elba Port Authority, Italy
}

\begin{abstract}
"ELBA" Eco-Friendly Mobility Services for People and Goods in Small Islands is a pilot project part-funded by the European Commission under the LIFE+Program, the EC financial instrument for the environment.

Launched in October 2010 and running until September 2013, ELBA has the main objective of planning, implementing and demonstrating a number of advanced, eco-sustainable, integrated mobility schemes and services for people and goods targeting, specifically, the "small islands" environment and application context.

In particular, the territorial context of the ELBA project includes the island of Elba, the main island of the Tuscan Archipelago (Tuscany Region, Italy) and the connected mainland area, including the town of Piombino (Livorno Province) and the surrounding regional transport environment.

Overall, ELBA investigates, implements and pilots a number of "intermediate" and "flexible" transport and logistics schemes, operated by ecofriendly vehicles, and promotes on the island of Elba the achievement of high standards of energy efficiency and environmental quality.

Keywords: environment, Small Islands, people, goods, transport, logistics, eco mobility, distribution, flexibility.
\end{abstract}

\section{Introduction}

\subsection{Objectives of the project}

Private traffic flows, taken together with commercial traffic flows and processes for goods transport and distribution, represent two of the primary sources of energy consumption, toxic gas emission and increased sound pollution in urban 
centres, of whatever size these may be. The effects on the environment, the health and the quality of life of citizens are well known. Such effects significant in the negative sense in all urban or peripheral areas - are equally critical (if not more so) in urban and rural environments such as small islands like those of the Tuscan Archipelago. Their areas of environmental, historical and tourist worth leave these islands more exposed to the impact and risk of deterioration caused by traffic.

"ELBA" Eco-Friendly Mobility Services for Peoples and Goods in Small Islands is a pilot project partly funded by the European Commission as part of the LIFE+programme, the EU financial instrument regarding the environment, and was selected along with around 100 other projects amongst the many presented for the LIFE+2009 awards competition.

ELBA faces up to the problems of the mobility of persons and of goods within the context of the real life of smaller islands, taking into consideration mobility on the island and on the mainland connected with the Elban basin, and studying the traffic flow of passengers and goods going to and from the port of Piombino and the principal ports of the island (Portoferraio, Rio Marina and Cavo). The objective of the project is to identify and experiment effective and sustainable answers to the typical problems regarding Elban mobility. These are short, frequent trips between the mainland and the island, intermodality of goods traffic flow, local traffic, the interaction between goods, local mobility and tourist flows, and so on.

Taken together, the ELBA project aims at an integrated approach based on varied intervention for sustainable, flexible transport, comprising:

- Flexible Transport Systems (FTS) for people (in different areas, and for usersectors to be identified, e.g. services in areas of low demand, for tourists, for hotels, etc.);

- Innovative logistics schemes for goods transit between Piombino and Elba and for the distribution of such goods within the island territory (consolidating the loading on the Piombino side, 'last mile' delivery services on the Elba side, reverse logistics, services aimed at particular categories - e.g. tourists, the elderly, etc.);

- Technological solutions (ICT) to support the practicality of the new services, which would include an IT platform for programming and managing services and a web portal for user information and services (including, for example, booking transport services, goods delivery tracking, a 'virtual market-place' for goods transport, etc). There would also be usage of ecologically-friendly vehicles (e.g. electric vans) for the sustainable management of ELBA passengers and goods services, and to guarantee reduced environmental impact $\left(\mathrm{CO}_{2}\right.$ emissions, local pollutants due to traffic, sound and vibration) and rationalised energy use.

Apart from the various subjects in the Elba area, one Greek island will work together as a research partner looking for effective and transferrable responses to other island realities, and contributing to the definition and verification of solutions at a European interest level. 
In total, the ELBA project will last 36 months (beginning from October 2010) and is organised following an activity structure that includes 26 Actions organised within the following "Macro Action" programme:

Macro Action 1: preparatory action;

Macro Action 2: implementation phase;

Macro Action 3: communication and promotion actions;

Macro Action 4: project monitoring and management.

\subsection{Expected results}

Expected positive results of the planned ELBA actions include:

- $\quad$ inducing a shift from private (car) mobility in the island by offering attractive public transport services operated by ecologically friendly vehicles;

- $\quad$ reducing the impact of incoming freight flows through rationalization and optimization of the delivery services already on the mainland side (freight consolidation services, optimized freight transport schedules, optimized load capacity in short sea transport mainland-island);

- rationalizing freight distribution ("last mile" delivery) and logistics services, e.g. inner logistics, outgoing freight flows) on the island of Elba by applying dynamic optimization strategies that adapt freight transport both to current demand and traffic conditions.

The envisaged solutions are tightly interrelated and will be part of an integrated mobility management scheme delivering different measures (addressing the above mobility components), operating through a common mobility service centre using flexible service provision, and optimization of transport and attractive services alternative to private transport.

The adoption of such schemes will positively contribute to reducing the adverse effects of current mobility processes and practice in passenger and goods transport, and will lead to relevant improvements for the environment as well as for the quality of life in Elba Island.

\subsection{Consortium}

The Port Authority of Palomino is the beneficiary of the ELBA project, and acts as the project co-ordinator and site demonstration responsible.

APP staff manages and coordinate relevant development projects, and with the collaboration of the ELBA project technical manager (Meme) and consortium partners, guarantee the required mix of competence and expertise needed for successful implementation of the planned ELBA project, and to match general programme requirements and adequate promotion and diffusion of results.

Rio Marina Council (Italy) guarantees the presence of Local Authorities in the consortium and will also contribute to the land planning aspects and normative issues. 
ATL - Livorno Transport Company Spa (Italy) manages both conventional (fixed lines and timetables) transport and demand responsive transport (DRT) services in the Livorno area (including the island of Elba).

Safeco Sis mat spa (Geneva, Italy) is the IT supplier responsible for implementation, localisation and deployment of the IT e-Services architecture for ELBA.

Meme sol (Livorno, Italy), transport and mobility consultancy services, investigation of city logistics operational schemes and business models.

The Council of Kalymnos or Port Authority of Corfu (Greece) will be involved in various actions of the LIFE+ELBA project, aiming to benefit from the know-how and practices to be developed and applied, considering their transferability to the Greek island context.

\section{The territorial reference system}

The definition and planning of ELBA services took as its point of departure the analysis of a common territorial reference system regarding both people and goods, that saw as a shared point embarkation from the mainland at the port of Piombino, and as an area of transport the territory of the island of Elba, and particularly its ports, road network and the various urban areas/tourist zones.

\subsection{The port of Piombino}

The port of Piombino is located centrally on the Tuscan coastline, at a short distance from the infrastructure of the multimodal Tyrrhenian corridor.

The port of Piombino is the only means of access to the mainland for the islands of the Tuscan Archipelago, in particular the island of Elba, the connection with the port of Livorno no longer being active.

As far as optimising the logistics processes related to distribution of goods on the island aiming at the urban centres is concerned, the port area of Piombino (or in any case the urban hinterland) is the ideal location for logistic collection, consolidation, and successive transport to the island, and the distribution itself.

Activities connected with optimising the management of goods distribution for urban areas of the island of Elba, which see the territory of Piombino as the point of goods collection and freight consolidation, are therefore to be included in the positive development and strengthening framework outlined above.

\subsection{The island of Elba}

The Island of Elba separates by convention the Tyrrhenian and Ligurian seas, and, given its environmental, landscape and cultural peculiarities, is part of the National Park of the Tuscan Archipelago.

With a surface area of around 242 sq. km., it is the largest island of the Tuscan Archipelago and the third largest in Italy. 


\subsubsection{The Elban ports}

The Elban ports which currently guarantee connections with the mainland (the port of Piombino) are those of Portoferraio, Rio Marina and Cavo (landing stage) that fall under the Port Authority of Piombino.

2.2.1.1 The port of Portoferraio The historic Darsena Medicea basin in Portoferraio is now for the use of pleasure craft, and the Calata Depositi and Alto Fondale quay form the preferred mooring for cruise ships, given their position in the historic centre, the ample parking space nearby for excursion coaches, and the fact that ships of notable size may tie up there.

The Calata Italia, linked to the Alto Fondale only by one connecting quay, stretches to the southernmost point of the port area, and accommodates three jetties destined as terminus for the ferries that link Portoferraio with the port of Piombino.

2.2.1.2 The port of Rio Marina The port of Rio Marina is situated on the eastern coast of the island. It is second to Portoferraio for the number of ferries arriving at the island. It owes its construction to the mineral exploitation of the eastern part of Elba, being the ideal embarkation point for material coming from the nearby mines, here to be loaded onto ships for transport. As the years passed by, wooden jetties gave way to loading piers built in iron, and a breakwater wharf that was lengthened on more than one occasion. With the decrease, and final end, of extractive activity, the port was abandoned and part of its loading structures removed, but the breakwater part of the port has been extended.

2.2.1.3 The Cavo landing stage The port of Cavo, situated on the northeastern tip of the island in a village that is part of Rio Marina council territory, is the port closest to the mainland, and thus the ideal point of arrival for ferry traffic to Elba.

\section{Routes of communication}

\subsection{Maritime communications}

As stated above, the port of Piombino is the principal means of access to the islands of the Tuscan Archipelago, and particularly the island of Elba, where the main port is obviously that of Portoferraio, followed by Rio Marina and the Cavo landing stage.

Currently, some $76-78 \%$ of ferry movement on connections with Piombino goes to the port of Portoferraio, with $14-17 \%$ going to Rio Marina and $8-5 \%$ to Cavo (the variations regard high and low seasons).

The development of the port of Piombino foreseen in the POT (Three Year Operative Plan) and the PRP (Port Regulatory Plan), along with the possibility of greater use of the port of Rio Marina, definitely represents a positive opportunity to improve connections between Piombino and the island of Elba, particularly for goods traffic. 


\subsection{Internal road network}

The road network of the Island of Elba is characterized by a perimeter road link between the principal centres of some $160 \mathrm{kms}$ in total, and a network of some $80 \mathrm{kms}$ of non-metalled roads, and the urban networks of the individual centres.

Most of the Elban road network, resulting in fact from the layout of Napoleonic times, features tortuous routes often characterised by high gradients, as a consequence of the morphology of the land, with sections of reduced width giving rise to an element making circulation difficult (particularly for buses and medium-size and heavy vehicles), this having a significant impact on overall mobility.

In any case, in almost all the inhabited centres there are narrow streets, sometimes with steep gradients (e.g. Capoliveri, Rio Elba, Marciana), which are not easy for commercial vehicles to pass through.

Finally, it should be remembered that particularly in the summer period prohibition of urban traffic circulation is often used, at different times and in different ways, in order to create or extend traffic-free areas and pedestrianised zones.

\section{The user basin for passenger transport services in the Elban territory}

\subsection{Residents}

On 31/12/10, the total resident population of the island was 32,097 inhabitants, that is 132.7 inhabitants per square kilometre. From the point of view of numbers of residents, Portoferraio is the main centre of the island, with a population of 12,253, followed by Campo nell'Elba with 4,651, then five councils with populations of between 2 and 4 thousand, and Rio nell'Elba, which, with a population of 1,244 , is the smallest centre.

\subsection{Tourist flows}

Already for many decades Elba has been a strong tourist attraction, chosen by domestic and foreign guests for the summer holiday period. Although, from the economic point of view, this is a relevant source of wealth for tourist operators and those who work in the sector, from the point of view of services it causes notable imbalances, with significant seasonal variations in many sectors, such as health, public transport, mobility, water supply, energy requirements, etc.

The major tourist flow evidently is in the period running from June to September. In particular, the months of July and August register the highest numbers of daily presences which, in the year 2010 for example, reached 22,891 and 25,682 respectively. This means that in these months the number of people on the island is almost doubled. The four months of the tourist season (June to September), in fact, see some 2.32 million presences on the island, equal to $85.4 \%$ of the annual total. 


\subsection{The demand for personal mobility}

As indicated in preceding sections, the demand for personal mobility within the Elban area is characterised by two main components: (i) residential mobility, characterised both by urban movement and that between the main island centres, with a constant pace, although closely connected to the annual school timetable; and (ii) mobility connected with tourist flow, with a relevant impact in the summer on the principal coastal centres.

As may easily be inferred, the structure and volume of the demand show a significantly seasonal character. Whilst this aspect is less relevant for urban areas (above all for the centre and periphery of Portoferraio), extra-urban mobility is affected by major fluctuations, obviously connected with the direct flow coming from tourist zones.

\subsection{The public transport network and offer}

Given the transport needs of residents and tourists, ATL offers public transport services both in urban areas (Portoferraio) and on the principal extra-urban routes throughout the island, on the basis of a specific, existent service contract with the province of Livorno.

ATL runs six lines within the urban area of the council of Portoferraio, operating on fixed routes and timetables which vary according to the season.

\section{Planning LIFE+ELBA services for passenger transport}

Studies and analyses that have been carried out relating to public transport services for the island of Elba have led to the identification of certain general objectives to improve the current situation, on a dual front:

(a) a rationalisation of public transport services, in particular during the summer peak - with a consequent reduction of their impact;

(b) an enhanced quality of the service offered, aimed at increasing its attraction and consequently bringing about a movement away from private transport towards sustainable forms of collective transport.

In other words, the objectives being followed consist of favouring/promoting alternatives to the use of the private car by residents and tourists (with particular reference to the summer period), and of managing such services in an ecologically compatible way, with low or zero impact.

In this context, the LIFE+ELBA project intends to create public transport services that make tourists desire to use public means of transport for moving around the island rather than their own cars.

Other than reducing private traffic in areas characterised by a narrow street network where there is scarce parking space, the success of these new services could also tempt those tourists who have planned a visit to the island of a few days to leave their cars in the long-term car parking built for the purpose at the port of Piombino, and so reduce the number of vehicles circulating on the island in the critical summer period. Such a result would require promotional activities 
aimed at the tourist prior to arrival on the island. Finally, the use of vehicles (minibuses) with low or zero emissions will further contribute to reducing overall impact.

\subsection{Elba LIFE beach service (north coast)}

The LIFE+ELBA work group identified an initial critical summer level for the circulation and parking of private vehicles along the northern coast of Portoferraio, related to the presence of a number of well-visited small beaches and bays there.

Many tourists stay in the various hotels of Portoferraio and travel daily, together with residents, to the various beaches. As no public transport service exists at present, the various areas are reached only by making use of private cars (or scooters), with the common phenomenon of traffic congestion and illegal parking all along the roadway, which - given the morphology of the area - is characterised by a narrow, winding carriageway. The lack of necessary parking spaces worsens the situation, with traffic frequently slowed by vehicles manouevring or looking for parking places.

In order to eliminate, or at least lessen, this problem, a public transport service has been studied and planned called "LIFE+ELBA BEACHES" along a circular route.

The frequency and timetabling of the planned service, together with the convenience of transport to the beaches and bays without the problems connected to traffic circulation and finding parking - which often mean having to cover long distances on foot - make it very competitive with respect to the use of private cars. This new means of access to the bathing sites of the northern coast of Portoferraio will have as a positive result the reduction in the number of cars in circulation, with lower levels of traffic congestion and illegal parking, and a consequent reduction in emissions and energy consumption, and an improvement in the environmental quality of the area, which notwithstanding the notable human presence has maintained certain elements of elevated naturalistic value.

Even in the case of future payment for bus tickets, the service will remain competitive even in the economic sense

\subsection{Elba LIFE beach service (eastern coast)}

With the reorganization of links between the island and the mainland, given the shift of part of the traffic onto Cavo, the work group uncovered the need to improve public transport services between this eastern area of the island and Portoferraio, and above all between various inhabited centres in this part of the island (Rio nell'Elba - Rio Marina - Cavo) - this also on the basis of specific needs shown by the Council of Rio Marina (a project partner).

Beyond facilitating connections with the mainland, strengthening this "entrance way" onto the island should bring about an increase in tourist presences in this part of the island in the summer period. The current public transport services are mainly oriented towards the requirements of residents, in 
particular when schools are open, but are not adequate to meet the needs of tourists and residents who travel daily between the inhabited centres and the beaches and bays of the zone.

The LIFE+ELBA EAST service also aims to meet the needs of those tourists who intend to stay on the island for a few days and are currently obliged to take their cars with them as they have no confidence in the public transport services.

\subsubsection{Ecological vehicles for carrying out the Elba LIFE beach services}

On the basis of the activities developed during the Clean Vehicles Selection, and with the experience that ATL has on the use of electrical vehicles, the work group has been in contact with the most important national producer of electrical vehicles (MicroVett of Imola) in order to gain an idea of the choices to be made and the solutions adopted.

An electric DUCATO minibus with a capacity of 18 passengers plus driver has been chosen following a phase of experimental testing on-site, so as to verify in a preliminary way the possibilities of its use. This vehicle, fully laden, will go up slopes of $18 \%$ and given its autonomy of more than 120 kilometres will be able to carry out the services foreseen, exploiting the gap between the morning and afternoon slots to recharge batteries.

The national normative for public transport does not provide for such a modality (renting) in acquiring vehicles for passenger transport, and ATL experienced some difficulties in obtaining all the mandatory homologation licenses from the relevant national offices. The positive solution, reached with a specific roadmap developed, has been attained thanks to collaboration among all the actors involved (ATL, MemEx, TIL - Renting Service provider, Motorizzazione Civile, Livorno Province, Portoferraio Municipality, etc.) and represents one of the first successful experiences in this field in Italy. In this sense, the administrative and technical solution successfully defined under the ELBA project for this purpose now represents a key reference case also at national level.

\subsubsection{The ICT Elba shuttle platform}

Planning the sustainable passenger mobility services ELBA+LIFE (BEACHES and EAST) also foresaw intense activity for the definition of ICT aspects destined for the planning, and real-time monitoring and reporting of the services supplied.

The "ElbaShuttle" platform is made up of different software modules, which allow ATL to programme and manage the planned services in the best possible way, by way of its FMC (Fleet Monitoring Centre), and in particular:

- ElbaShuttle service set-up

- Service planning

- Definition of frequency and timetables

- Definition of the route (stops, target points, etc.).

- Definition of the fleet.

- Real time monitoring of the vehicles, with a visualization of their position on the network, and the possibility of sending alarm signals.

- Statistics and reporting. 
- Journey graphic visualization, in:

- History view modality

- Playback view modality

The technology partners have also set up apposite QR codes placed on the posts at the stops and all the information panels which, by using a smart phone/tablet (Android), allow a direct connection to the www.atl.livorno.it site, where it is possible to get all necessary information, and to download specific applications in order to receive detailed information about the new service.

\section{Planning LIFE+ELBA services for goods movement}

\subsection{The user basin for goods transport services on Elban territory}

The second aspect of mobility that the LIFE+ELBA project considered concerns 'last-mile' goods transport. The project in fact foresees a series of actions aimed at rationalizing the distribution and transport process (the 'last mile' of the transport chain) and logistical services (e.g. internal logistics, exit flow) on the island of Elba. This is done thanks to the application of management models and strategies for dynamic optimisation better able to discipline goods transport flow on the basis of the seasonal variability of demand.

As a general rule, small islands not far from the mainland may be assimilated to urban areas (although in reality there are small population agglomerations spread throughout the territory), and so problems connected to the process of delivery/withdrawal of goods may be approached using schemes derived from city logistics, suitably adapted to take into account specific factors linked to a) the presence of the marine stretch, and b) the seasonal nature linked to the tourist vocation shown by these territories.

The application of innovative logistics services for distribution/withdrawal of goods cannot but spring from the adoption of instruments that also take into account those aspects connected to the particular environmental value of these areas, often subject to human pressures linked to traffic flow (goods and passengers) that are concentrated during the few months of the summer period.

\subsection{The demand for goods mobility}

In order to understand the dimension of the general demand for goods transport to the island, and their subsequent distribution throughout the territory, the study phase began with data collection and analysis of an economic nature, in particular so as to identify the number of businesses present on the island. This revealed a strong concentration of the latter within the territory of the Council of Portoferraio, where more or less one-third of the total is to be found.

Regarding goods mobility, logistical services were studied and planned both for the Piombino and the island of Elba 'sides'.

The following services were developed:

The "LIFE+ELBA FREIGHT" service, working with the 'Corriere Fulceri', through which operative procedures for the following were defined: 
- $\quad$ A service for the initial collection and consolidation of loads destined for the island of Elba in the experimental logistics base in Piombino:

- $\quad$ A planning service for delivery and secondary optimisation of loads by way of the ICT platform, to be carried out at the experimental logistics base in Piombino;

- A 'last mile' service for the distribution of goods received at the Piombino base or collected at Portoferraio by way of the experimental logistics base at Portoferraio, operating with electric vehicles for the Portoferraio area and with bi-powered vehicles for the rest of the island;

- A "reverse logistics" service for goods exiting the island, operating with electric vehicles for the Portoferraio area and hybrid vehicles for the rest of the island;

- $\quad$ Mounting black boxes on the vehicles used in the experimentation (buses and vans) for their real time monitoring;

- $\quad$ Contacts with telecom providers for data transmission;

- Installation of HA and SW apparatus at the offices of ATL and logistics operators.

The demonstrative logistics service, called "LIFE+ELBA LAUNDRY", for the management and delivery/withdrawal of clean and dirty laundry from hotels and restaurants, developed in the summer period together with the ILVA s.r.l. industrial launderer, allowed a study of the management of particular problems, such as covering larger distances with extra-urban characteristics, the entrance into historic centres with traffic limitation following timetables laid down by the different Elban councils, load management on the basis of the differing customer needs during seasonal peak time, optimisation of route and load to avoid the socalled "empty runs", etc.

The ecologically sustainable service for goods transport "LIFE+ELBA FREIGHT II" (sorting products from the production plant through to the various points of sale, located all over Elban territory) and "LIFE+ELBA ELECTRONICS", developed and implemented together with Eltimar Supermercati s.a.s. of Portoferraio.

This latter type of service was useful substantially in order to verify an economic sector where seasonal phases are of less importance, and the trend remains constant throughout the year.

\subsection{Ecological vehicles to carry out the Elba LIFE FREIGHT services}

In order to select the most suitable vehicles to carry out goods transport services, it was immediately evident that the lack of service stations on the island supplying LPG and CNG obliges the choice of ecological vehicles of electrical or hybrid type.

The results of this research allowed the identification of two types of ecological means suited to carry out the activities foreseen for the experimentation with goods traffic. These were an electric Porter Blind Van to deliver goods in the Portoferraio area, and a bi-powered Fiat Iveco Daily Cargo for distribution throughout Elban territory. 


\section{Conclusion}

Very positive results have come from the experimentation carried out, both as regards passenger transport services and those for goods.

The bus shuttle for the beaches, for example, raised great enthusiasm amongst users and allowed notable limits to be set on the use of private cars in areas that are habitually traffic congested. For this reason, once the project has finished, it is to be hoped that local institutions and possibly private partners will be active in order to finance logistical services similar to those identified, which supplied a valid alternative to private means of transport. This would bring about significant progress from the point of view of the environment, economic savings, and improvement to the quality of life for residents.

Significant consideration regarding the work carried out should also be given to the topic of the awareness of local bodies. In order to ensure that many aspects of local mobility are improved, it is important that such bodies become an active and collaborative part of a structured system, both concerning the regulation of areas of traffic limitation and the promotion of initiatives aimed at encouraging the usage of services.

It should be noted that the various studies undertaken include analyses of aspects of the management and economics of organised structures aimed at running services for ecologically positive mobility, and the formulation of hypotheses on various possible company structures, organisational set-ups, and a business model that could manage the system.

The solutions put into action for the project will, once the experience has been completed, form a useful instrument on which to draw for best practices that are transferrable to all island realities possessing similar characteristics to those of the territory examined. 